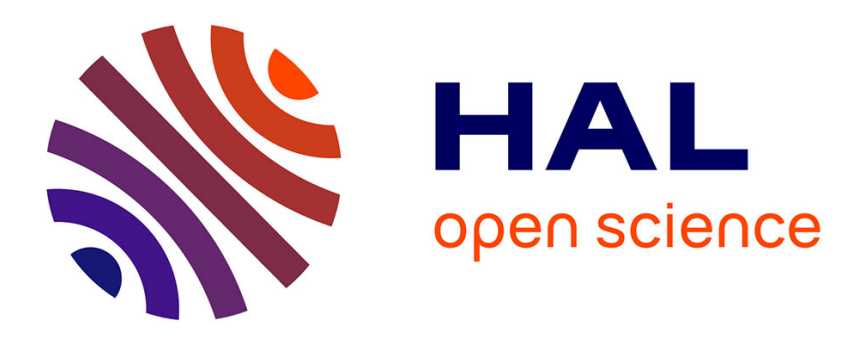

\title{
THE BORDONI RELAXATION - THREE VALLEYS MODEL
}

G. Haneczok, Gilbert Fantozzi

\section{To cite this version:}

G. Haneczok, Gilbert Fantozzi. THE BORDONI RELAXATION - THREE VALLEYS MODEL. Journal de Physique Colloques, 1985, 46 (C10), pp.C10-277-C10-280. 10.1051/jphyscol:19851061 . jpa-00225445

\section{HAL Id: jpa-00225445 https://hal.science/jpa-00225445}

Submitted on 1 Jan 1985

HAL is a multi-disciplinary open access archive for the deposit and dissemination of scientific research documents, whether they are published or not. The documents may come from teaching and research institutions in France or abroad, or from public or private research centers.
L'archive ouverte pluridisciplinaire HAL, est destinée au dépôt et à la diffusion de documents scientifiques de niveau recherche, publiés ou non, émanant des établissements d'enseignement et de recherche français ou étrangers, des laboratoires publics ou privés. 
JOURNAL DE PHYSIQUE

Colloque C10, supplément au $\mathrm{n}^{\circ} 12$, Tome 46 , décembre 1985 page $\mathrm{C} 10-277$

THE BORDONI RELAXATION - THREE VALLEYS MODEL

\author{
G. HANECZOK* AND G. FANTOZZI
}

+ Institute of Physics and Chemistry of Metals, Silesian Univ. 40-007 Katowice, Poland GEMPPM - INSA - UA 341 - Bât. 502, 20 Avenue Albert Einstein, 69621 Villeurbanne Cedex, France

Résumé - Une méthode analytique du calcul du frottement intérieur da à la formation des doubles décrochements est développée à partir de la théorie cinétique dans le cas de trois vallées de potentiel. Le modèle permet de décrire correctement les résultats expérimentaux, à condition que la dislocation ne franchisse pas de trop nombreuses vallées de potentiel.

Abstract - The analytical description of internal friction related to the double-kink relaxation is obtained applying the kinetic theory in the case of three potential valleys. This model can describe experimental curves in the case in which dislocations do not pass by many potential valleys.

I - INTRODUCTION

The aim of the paper is to obtain an analytical description of the relaxation related to a thermally activated process of double-kink formation on dislocations (Bordoni relaxation). The starting point of our analysis is based on results obtained from application of the kinetic theory.

The model of two potential valleys $(i=2)$ is oversimplified and does not give complete description of the experimental data $/ 1 /$. Therefore we decided to elaborate a three potential valleys model which enables to obtain an analytical expression for internal friction $Q^{-1}$ for a case in which the applied stress $\sigma$ is much smaller than internal stresses $\sigma_{j}$.

II - DESCRIPTION OF THE THREE POTENTIAL VALLEYS MODEL

In the case of three potential valleys the system of the kinetic theory equations may be written as:

$$
\begin{aligned}
& \dot{n}_{0}=-n_{0} k^{\prime} 01+n_{1} k^{\prime} 10 \\
& \dot{n}_{1}=n_{0} k^{\prime} 01-n_{1}\left(k^{\prime} 10+k^{\prime} 12\right)+n_{2} k^{\prime} 21 \\
& \dot{n}_{2}=n_{1} k^{\prime} 12-n_{2} k^{\prime} 21
\end{aligned}
$$

where $n_{j}$ is the occupation probability of a $i-t h$ potential valley by the dislocation.

The jump frequences $k^{\prime} i, j$ from $i$-th to $j$-th valleys are given by:

$$
\begin{aligned}
& k^{\prime} i, i-1=k o \exp \left[-\left(E_{a}(i)+v_{a}(i) g\right) / k T\right] \\
& k^{\prime} i, i+1=k 0 \exp \left[-\left(E_{c}-v_{c} \sigma\right) / k T\right] . \\
& k_{0} \simeq \nu_{D} / 100
\end{aligned}
$$

in which $\nu_{D}$ is the Debye frequency and $\sigma$ the applied stress $\left(\sigma \ll \sigma_{j}\right), E_{C}, V_{C}$ are energy and volume for double-kink formation respectively and $E_{a}, V_{a}$ the double-kink annhilation energy and volume. 
Solution of the equations system (1) may be written as:

$$
n_{i}=\sum_{1} \gamma_{1} \exp \left(-t / \theta_{1}\right) \alpha_{i}^{\top} \quad i, 1=0,1,2
$$

where :

$$
\alpha_{0}^{1}=1, \quad \alpha_{1}^{1}=\frac{k^{\prime} 01 \theta_{1}-1}{k^{\prime} 10 \theta_{1}} \quad 1=\frac{k^{\prime} 01_{1}-1}{k^{\prime} 21 \theta_{1}-1} \frac{k^{\prime} 12}{k^{\prime} 10}
$$

The relaxations time $\theta_{0}=\infty$ corresponds to the equilibrium state $\left(\dot{n}_{j}=0\right)$ for $\sigma \neq 0$ in which $n_{i}=n_{i}^{e^{\prime}}$. The other two relaxation times $\theta_{1}$ and $\theta_{2}$ are equal :

$$
\theta_{1}=2 /\left(A+\sqrt{A^{2}-4 B^{1}}\right), \quad \theta_{2}=2 /\left(A-\sqrt{A^{2}-4 B^{\prime}}\right)
$$

where :

$$
A=k^{\prime} 01+k^{\prime} 10+k^{\prime} 12+k^{\prime} 21, B=k^{\prime} 01^{\prime} 12+k^{\prime} 21^{\prime} 10+k^{\prime} 0 k^{\prime} 21
$$

Three constants $\gamma_{1}$ are determined from the initial condition

$$
n_{0}(0)=n_{0}^{e}, n_{1}(0)=n_{1}^{e}, n_{0}(\infty)+n_{1}(\infty)+n_{2}(\infty)=1
$$

where $n_{j}^{e}$ are the equilibrium $n_{j}$ values for $\sigma=0$.

Having the solution of the equations system (1) we can write. an expression for anelastic deformation $\varepsilon_{a n}$ related to the double-kink formation.

$$
\varepsilon_{a n}(t)=N \sum_{i}\left(v_{c}+v_{a}(i)\right)\left(n_{j}(t)-n_{j}^{e}\right)
$$

where $N$ is the number of dislocations in a unit volume. After insertion of (3) in (5) we obtain:

$\varepsilon_{a n}(t)=N\left(v_{c}+v_{a}(1)\right)\left[\gamma_{1}\left(1-v_{1} \alpha_{2}^{1}\right)\left(1-e^{-t / \theta_{1}}\right)+\gamma_{2}\left(1-v_{1} \alpha_{2}^{2}\right)\left(1-e^{-t / \theta_{2}}\right)\right]$

where $v_{1}=\frac{v_{c}+v_{a}(2)}{v_{c}+v_{a}(1)}$

Thus we obtained two relaxation processes relatied to $\theta_{1}$ and $\theta_{2}$.

Using a linear approximation for coefficient $k^{\prime} i, j$, expressions for intensities $\Delta_{1}$ and $\Delta_{2}$ of the two relaxation processes related to two relaxation times $\theta_{1}$ and $\theta_{2}$ may be obtained :

$$
\begin{aligned}
& \Delta_{1}=N \frac{\theta_{1} G\left[V_{c}+V_{a}(1)\right]^{2}}{\left(\theta_{2}-\theta_{1}\right) k T}\left[k_{01} \theta_{2}-\left(n_{2}^{e}+n_{1}^{e}+n_{2}^{e} V_{1}\right)\right]\left[n_{0}^{e}-V_{1} \frac{k_{01} \theta_{1}-1}{k_{21} \theta_{1}-1} n_{1}^{e}\right] \\
& \Delta_{2}=N \frac{\theta_{2} G\left[V_{c}+V_{a}(1)\right]^{2}}{\left(\theta_{2}-\theta_{1}\right) k T}\left[\left(n_{2}^{e}+n_{1}^{e}+n_{1}^{e} V_{1}\right)-k_{01} \theta_{1}\right]\left[n_{0}^{e}-V_{1} \frac{k_{01} \theta_{2}-1}{k_{21} \theta_{2}-1} n_{1}^{e}\right]
\end{aligned}
$$

Internal friction $Q^{-1}$ may be then calculated from the formula :

$$
Q^{-1}=\Delta \frac{\omega \theta_{1}}{1+\omega^{2} \theta_{1}^{2}}+\Delta_{2} \frac{\omega \theta_{2}}{1+\omega^{2} \theta_{2}^{2}}
$$

where $\omega$ - the angular frequency. 


\section{III - RESULTS AND DISCUSSION}

Four I.F. curves calculated from the formula (8) are presented in Fig. 1 (IF, temperature $T^{\prime}$ and dislocation strength $L^{\prime}$ are normalized). We can note that in cases 1 and 4 only two valleys play a significant role and the probability of occupation of the third one " 0 " or "2" can be neglected. For cases 2 and 3, all three valleys play relatively significant role and total curve is composed of two processes. Fig. 2 presents the variations of three normalized parameters characterizing the If peak - its height $Q^{-1} M N$, maximum temperature $T^{\prime} M$ and its broadening factor $\alpha$ as a function of L'. The suitable energetic diagrams are presented schematically.

It $c$ an be seen that if a Paré condition is fulfilled the broadneing factor $\alpha \cong 1$; the peak temperature $T^{\prime} M$ decreases when $C$ increases and is constant when $L$ ' increases. For a given loop length $Q^{-1}$ MN decreases with $\sigma_{j}$ which is connected with the reduction of the area swept out by the dislocations as the number of double kinks increases $11 /$. For constant $\sigma i, Q^{-1} M N$ increases as a function of $L^{\prime}$ according, in the first approximation, to relation $Q^{-1} M N \sim\left(V_{C}+V_{a}(1)\right)^{2}$.

The minimum of $Q^{-1}$ MN represents a deviation from the Paré condition. At this point $\alpha$ assumes its maximum value and $T^{\prime} M$ is a function of $L^{\prime}$ and $\sigma_{i}$. The evolution of those parameters is related to the variation of energetic diagrams, so it is connected with a distribution of relaxation times. From Fig. 2 it can be seen that results obtained using formula (8) are consistent with results obtained in paper $/ 2 /$ for $\sigma$ so and $L$ relatively small. So, calculations of IF, curves from the formula (8) show that:

1. The intensity of the total $Q^{-1} / T /$ curve passes trough a maximum for the fulfilled Paré condition $\left(E_{\mathrm{C}}=E_{\mathrm{a}}(i)\right)$.

2. If the first Paré condition $\left(E_{C}=E_{a}(1)\right)$ is fulfilled then the total curve will be controlled by the longer relaxation time, i.e. $\theta_{2}\left(\Delta_{2} \gg \Delta_{1}\right)$.

3. If the second Pare condition $\left(E_{C}=E_{a}(2)\right)$ is fulfilled then the total curve will be controlled by the shorter relaxation time i.e. $\theta_{1}\left(\Delta_{1} \gg \Delta_{2}\right)$.

4. If $E_{a}(2)<E_{c}<E_{a}(1)$ the total curve consists of a composition of two processes and in some particular cas two separate maxima can occur.

It seems that formula (8), after integration with a distribution of internal stresses and/or length of dislocation segments may be used to describe experimental curves determined for relatively large deformations $-\sigma_{j}$ then relatively large, $L$ small and dislocations forming double-kink do not pass through many potential barriers. In this case using a fitting method of theoretical model parameters we should obtain some information about parameters of loop lengths and internal stresses distributions.

\section{REFERENCES}

/1/ Esnouf, C., Thesis, Université de Lyon (1978).

/2/ Esnouf, C., Fantozzi, G., Phys, stat. sol., 47 (1978) 201. 


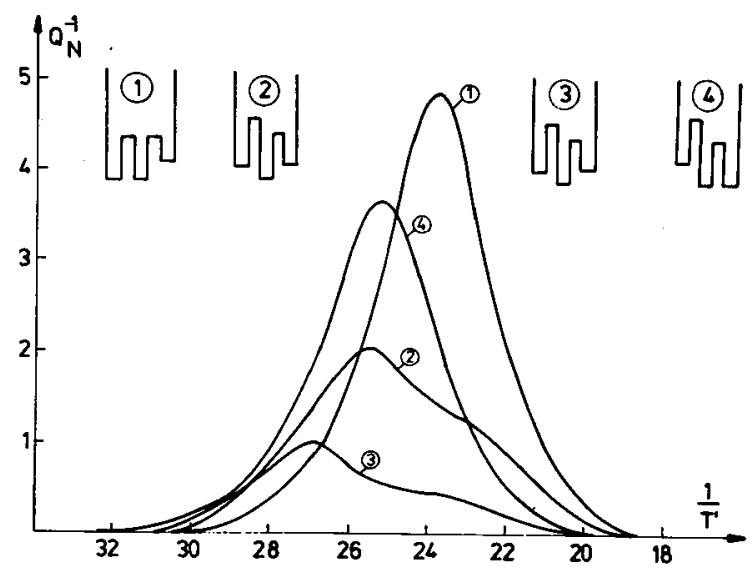

Fig. 1. - IF curves calculated using formula (8) for a double-kink energy $2 W_{k}=0.1 \mathrm{eV}, F=100 \mathrm{~Hz}$ and $1: L^{\prime}=5, C=\sigma i / \sigma p=0.1 ; 2: L^{\prime}=5.7, C=0.1 ; 3: L^{\prime}=5$, $C=0.118 ; 4: L^{\prime}=5, C=0.132$. The suitable energetic diagrams are presented schematically.

$\left|\begin{array}{l|l|l|l|l|l|}(2) \\ n^{(2)}\end{array}\right|$

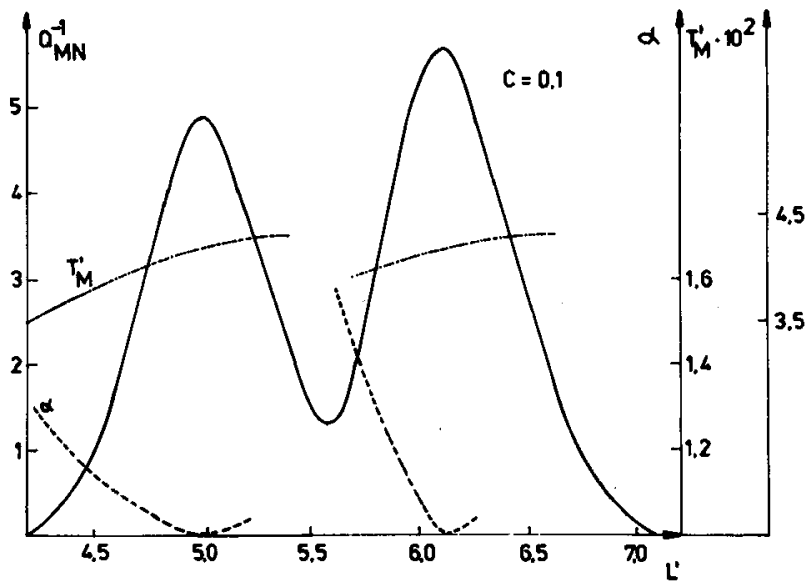
Fig. 2. - Variation of $Q^{-1} M^{-1}, T^{\prime},{ }^{\prime}$, a with $L^{\prime}$
$\left(C=0.1,2 W_{k}=0.1 \mathrm{eV}, F=100 \mathrm{HZ}\right)$. 